\title{
ANALISIS DE LA SECCION 8 DEL CROMOSOMA X DE Drosophila melanogaster MEDIANTE EL USO DE CLONES YAC DE Saccharomyces cerevisiae*
}

\author{
(Analysis of section 8 of X chromosome from Drosophila melanogaster \\ by use of YAC clones in Saccharomyces cerevisiae)
}

\author{
Blanca Urzúa ${ }^{1}$ Tito Ureta ${ }^{1}$ \\ Víctor Cifuentes ${ }^{2}$ \\ 1: Laboratorio de Bioquímica y Biología Molecular \\ 2: Laboratorio de Genética,Facultad de Ciencias, \\ Universidad de Chile. \\ Las Palmeras 3425, Santiago, Chile.
}

Palabras clave: Cromosomas artificiales, Saccharomyces cerevisiae, hexoquinasa A.

Key words: Artificial chromosomes,Saccharomyces cerevisiae, hexokinase A.

\section{RESUMEN}

En Drosophila melanogaster, los genes estructurales que codifican para hexoquinasas $A$ y $B$, se ubican estrechamente ligados en el cromosoma I (X). Estos loci corresponden a la región citológica 8D \$-El en el mapa citogenético de dicho cromosoma.

Con el objetivo de determinar la ubicación exacta de los loci para hexoquinasas $A$ y $B$ se realizó un análisismolecular, mediante el uso de cromosomas artificiales de levadura, que contienen DNA de la sección 8 del cromosomaX. Para tal efecto, se aisló DNA cromosómico intacto de siete clones $\mathrm{LAC}$ de $\mathrm{S}$. cerevisiae que cubren dicha región. El DNA fue resuelto mediante electroforesis de campo pulsado y analizado por hibridación con $D N A$ del plásmido $p B R 322$ y con un fragmento de DNA de 0,67 Kb de D. melanogaster, amplificado por PCR con partidores heterólogos especificos para hexoquinasas.

Los resultados de estos experimentos permitieron concluir que, la sonda homóloga es capaz de hibridar con el YAC II, lo cual coincide con la cobertura de este clon en la región citológica esperada.

\section{INTRODUCCION}

Los cromosomas artificiales de levadura fueron construidos, comouna alternativa al empleo de cromosomas. naturales, para el estudio de las relaciones entre la estructura cromosómica y el comportamiento de los mismos

\section{SUMMARY}

In Drosophila melanogaster the structural genes that code for hexokinases $A$ and $B$ are located closely together in chromosome I (X). These loci correspond to the $8 D t-E 1$ cytological region in the genetic map of this chromosome.

A molecular DNA analysis of the section 8 of the Xchromosome wascarried out to determine the location of the loci for hexokinase $A$ and $B$, by the use of artificial yeast chromosomes. To do this, intact chromosomal DNA of seven YAC clones of $\boldsymbol{S}$. cerevisiae was isolated. The DNA was resolved by pulsed field gel electrophoresis and then, analyzed by hybridization with DNA of the pBR322 plasmid and with a $0.67 \mathrm{~kb} D N A$ fragment from D. melanogaster, amplified by PCR with heterologous primers specific to rat hexokinase. The results suggest that the homologous probe hybridized with the YAC II, which is in agreement with the cytologic region where the Drosophila hexokinase $A-B$ genes are located.

durante la meiosis (Murray et al, 1983). Los cromosomas artificiales consisten de dos brazos que contienen los elementos funcionales constituyentes, esto es, los centromeros (CEN), que entregan información que actúa en cis, la cual es requerida para la separación adecuada durante los procesos de mitosis y meiosis (Burke, 1990).

* : Financiado por el proyecto Fondecyt 2920001 
Los telomeros (TEL) que corresponden a secuencias necesarias para la formación y mantención de cromosomas lineales, las secuencias de replicación autónoma (ARS), que actúan como origenes de replicación en las células de S. cerevisiae y dos marcadores genéticos de levadura, los cuales pueden ser el gen URA.3 y TRP1, que están en lados opuestos del sitio de clonado (Burke et al, 1991). Estos vectores de clonamiento permiten la introducción de grandes fragmentos de DNA que varían entre 100 y 800 $\mathrm{kb}$ y' se propagan en forma estable en $\boldsymbol{S}$. cerevisiae (Burke et al, 1987). La introducción de los YAC como un sistema de clonamiento de DNA ha sido una de los avances mas importantes en el estudio de los genomas (Burke et al, 1987), ya que entrega una herramienta para cl clonamiento e identificación de fragmentos muy grandes de DNA de regiones cromosómicas de diferentes organismos, incluyendo el hombre (Burke et al, 1987). Insertos de DNA de mayor tamaño (de aproximadamente $40 \mathrm{~kb}$ ), se lograban clonar en cósmidos, sin cmbargo, los YAC han aumentado el tamaño de los insertos en 10 a 20 veces, e incluso se puede considerar que no ticnen límite tcórico. Debido a su gran tamaño, la estimación de los inscrtos en los YAC se realiza mediante electroforesis de campo pulsado.

Los YAC han sido utilizados para identificar secuencias que se sobreponen como parte del proyecto del genoma de Caenorabditis elegans (Coulson et al, 1988). En Drosophila melanogaster, YACs portadores de DNA genómico, extraídos de geles de electroforesis de campo pulsado, han sido utilizados en cxperimentos de hibridación in situ para determinar su ubicación en el mapa cromosómico (Garza et al, 1988).

En Drosophila, cada brazo cromosómico principal está dividido en 20 secciones numcradas. El cromosoma $\mathrm{X}$ acrocéntrico, comprende las secciones 1-20, el cromosoma 2 las secciones 21-40 (brazo izquicrdo) y 41-60 (brazo derecho) y el cromosoma 3 las secciones 61-80 (brazo izquierdo) y 81-100) (brazo derecho). El pequeño cromosoma 4 comprende las secciones 101-102. A su vez, cada sección numerada está dividida en seis subdivisiones letradas (A-F) y cada subdivisión letrada contiene un promedio de alrededor de 9 bandas (en el rango de 2 a 28 bandas). Dentro de cada subdivisión letrada, las bandas se enumeran secuencialmente, de izquierda a derecha (Hartl, 1992., Ajioka, 1991). Así la región 8D4-E1, que señala la ubicación de los genes Hex A-B, significa que el o los genes caen en un punto no definido desde la cuarta banda de la izquierda en la subdivisión $\mathrm{D}$, hasta la primera banda de la izquierda de la subdivisión E. cn la sección 8 del cromosoma X de Drosophila (ver figura 1).

En el presente trabajo se utilizan siete clones de $S$. cerevisiae portadores de YACs, con insertos de DNA de Drosophila que definen la región citológica 8D4-E1, para determinar la ubicación de un fragmento de DNA sintetizado mediante reacción en cadena de la polimerasa (PCR) a partir del DNA genómico de la cepa silvestre Oregón R de Drosophila melanogaster.

\section{MATERIALES Y METODOS}

\section{Cepas.}

En este estudio se utilizó la cepa $\mathrm{AB} 1380$ de Saccharomyces cerevisiae como estándar (Carle et al, 1986). Los clones DYN04-21, DYE01-42, DYR07-36, DYN28-60, DYR16-01, DYR19-61 y DYN17-61 portadores de YAC de $370 \mathrm{~kb}$, de $325 \mathrm{~kb}$, de $350 \mathrm{~kb}$, de 260 $\mathrm{kb}$, de $210 \mathrm{~kb}$, de $230 \mathrm{~kb}$ y de $180 \mathrm{~kb}$ respectivamente de S. cerevisiae fueron proporcionados por el Dr. Ian Duncan, Washington University. La cepa silvestre Oregón-R de la especie Drosophila melanogaster, obsequiada por el Dr. Danko Brncic de la Facultad de Medicina de la Universidad de Chile, fue utilizada para extaer DNA.

\section{Condiciones de cultivo.}

Las cepas de $\boldsymbol{S}$. cerevisiae, fueron cultivadas a 30 ${ }^{\circ} \mathrm{C}$ en medio YCD (Base de nitrógeno de levadura $0.67 \%$, cascína hidrolizada $0.5 \%$, glucosa $1 \%$, ) con agitación conștante. Los suplementos nutricionales (animoácidos y adenina) fucron agregados a una concentración final de 20 a $60 \mathrm{mg} / \mathrm{ml}$.

\section{Preparación de DNA cromosómico intacto de Saccharomyces cerevisiae.}

EI DNA cromosómico intacto fue preparado por el método del bloque de agarosa (Schwartz \& Cantor, 1984) con algunas modificaciones. $5 \times 10^{9}$ células (en $50 \mathrm{ml}$ de cultivo) de la cepa $\mathrm{AB} 1380$ y los distintos clones portadores de cromosomas artificiales de $\boldsymbol{S}$. cerevisiae, fueron precipitadas por centrifugación a $4^{\circ} \mathrm{C}$ y $3.000 \mathrm{rpm}$ durante $10 \mathrm{~min}$. Luego fucron lavadas tres veces con

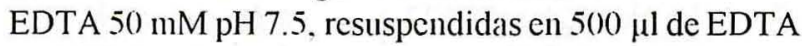
$50 \mathrm{mMc}$ incubadas por 3 a $5 \mathrm{~min} \mathrm{a} 45^{\circ} \mathrm{C}$. Posteriormente, se agregó $35 \mu \mathrm{l}$ de zymoliasa 100T a una concentración de $2 \mathrm{mg} / \mathrm{ml}$ einmediatamente tres volúmenes de una solución de agarosa de bajo punto de fusión al 1.3\% en EDTA 125 $\mathrm{mM} \mathrm{pH}$ 7.5. La mezcla fue agitada suavemente hasta homogeneizar la solución, depositada en moldes plásticos de $0,2 \mathrm{ml}$ e incubada a $4^{\circ} \mathrm{C}$ por 5 a $10 \mathrm{~min}$. Luego, los bloques fueron incubados en $5 \mathrm{mlde}$ tampón LET (Schwartz \& Cantor, 1984) durante 24 h a $37^{\circ} \mathrm{C}$. Posteriormente, los bloques fueron lavados tres veces con EDTA $50 \mathrm{mM} \mathrm{pH}$ 8,0 c incubados en $2 \mathrm{ml}$ de tampón NDS a $55^{\circ} \mathrm{C}$ por 24 horas. Finalmente, los bloques fueron lavados 3 veces con EDTA 50 mM a tcmperatura ambiente y fueron guardados en EDTA $50 \mathrm{mM} \mathrm{pH} 7.5$ a $4^{\circ} \mathrm{C}$ por períodos cortos, o indefinidamentc a $-20^{\circ} \mathrm{C}$ en EDTA $25 \mathrm{mM}, 50 \%$ glicerol. 
Electroforesis de campo pulsado.

La electroforesis de campo pulsado fue realizada en un equipo BioRad CHEF DRII usando un electrodo hexagonal. Los geles fucron preparados con agarosa al $1,0 \%$ en tampón TBE 0,5X (Sambrook et al, 1989). Para la corrida electroforética se utilizó tampón TBE $0.5 X$. La temperatura del gel y del tampón de electroforesis fue mantenida a $14^{\circ} \mathrm{C}$ y con circulación constante. Los bloques de agarosa fueron depositados en los pocillos del gel y luego sellados con agarosa al 1\% cn tampón TBE. Las condiciones de electroforesis fue con pulsos de 70) seg por 24 horas y $120 \mathrm{seg}$ por 11 horas a 165 volts. Los geles fueron teñidos con bromuro de etidio $(1 \mu \mathrm{g} / \mathrm{ml})$ durante 60 min, luego desteñidos con agua destilada durante el mismo tiempo. El tamaño de los cromosomas artificiales fue determinado usando DNA de la cepa ABI380 de $S$. cerevisiae como patrón.

\section{Hibridación de DNA.}

La hibridación de DNA fue realizada mediante la técnica de Southern (Southern, E. 1975), tal como lo describe Sambrook et al, (1989). El DNA fue transferido desde los geles de agarosa a membranas de nylon (BRL) durante 10 a 12 horas, usando tampón de transferencia SSC $10 \mathrm{X} \mathrm{pH} 7(\mathrm{NaCl} 1.5 \mathrm{M}$ y citrato de sodio $0.15 \mathrm{M})$ y luego fijado a la membrana mediantc irradiación con luz UV de $302 \mathrm{~mm}$, durantc $5 \mathrm{~min}$. La pre-hibridación del DNA fue realizada en SSC $5 \mathrm{X}(\mathrm{NaCl} 0.75 \mathrm{M}$ y citrato de sodio $0.075 \mathrm{M}$ ), formamida al $45 \%$, Denhard $5 X$ (ficoll al $1 \%$, PVP al $1 \%$, BSA al $1 \%)$, SDS al $0,5 \%$ y $100 \mu \mathrm{g} /$ $\mathrm{ml}$ de DNA de esperma de salmón. Como sonda radiactiva se utilizó un fragmento PCR de $(0.67 \mathrm{~kb}$ de D. melanogaster, clonado en pBlucscript SK (+/-). La sonda de DNA fue marcada radiactivamente (a una actividad específica de 2 $\times 10^{8} \mathrm{cpm} / \mu \mathrm{g}$ de DNA) con (alfa' ${ }^{32} \mathrm{P}$ ) dCTP mediante el método de partidores al azar, descrito por Fcinberg (1983). La hibridación fue realizada en la misma solución de prehibridación, en presencia de 50 ng de la sonda radiactiva, a $42^{\circ} \mathrm{C}$ con agitación suave durante 10 horas. Posteriormente, las membranas de nylon fueron lavadas en condiciones de alta estrictez y sometidas a autoradiografía a $-70^{\circ} \mathrm{C}$ durante 24 a 48 horas y reveladas de manera rutinaria.

\section{RESULTADOS Y DISCUSION}

Cobertura de los cromosomas artificiales de levadura (YAC) en el DNA genómico de la sección 8 del cromosoma X de Drosophila.

Los genes que codifican para hexoquinasas $\mathrm{A}$ y $\mathrm{B}$ en D. melanogaster, han sido localizados genćticamente a través del cruzamiento de moscas con algunas variantes electroforćticas. A partir de este tipo de análisis, se conoce la ubicación de dichos genes en el mapa citogenético de Drosophila. Para realizar el análisis de la sección 8 del cromosoma X de D. melanogaster, se utilizaron siete clones YAC que han sido localizados a través del proyecto de secuenciación del genoma de Drosophila con clones YAC (Ajioka, 1991; Haini, 1994), mediante hibridación in situ, en la región citológica 8D4-E1 (Voelker et al, 1978). En esta región se ubican los genes Hex A-B. La figura 1 muestra un esquema de la organización de la región 8D4-El y la ubicación de los YACs. La tabla 1 resume algunas características relevantes respecto de los mismos.

Los clones DY, son cromosomas artificiales de levadura que contienen DNA genómico de embrión de Drosophila digerido con la enzima NotI, y fueronclonados en el vector pYAC5. En cambio, los clones DYR y DYE portan DNA genómico de moscas adultas parcialmente digerido con la enzima EcoRI y fueron clonados en el vector pYAC4.

En la figura 1, que muestra la cobertura de los diferentes clones YAC, se aprecia que sólo una pequeña parte de la sección $8 \mathrm{del}$ cromosoma $\mathrm{X}(8 \mathrm{C} 3-13)$ no queda cubierta por éstos, aún cuando, según la ubicación citológica determinada para los genes Hex A-B, la mayor parte de los YAC caen en esta región (sombreada en el esquema de la figura 1).

\section{Ubicación de los cromosomas artificiales (clones YAC) en el genoma de la levadura.}

Con el objetivo de determinar la ubicación de los clones YAC en el cariotipo clectroforćtico de la levadura, se realizó electroforesis de campo pulsado de cada una de las cepas de $S$. cerevisiae, portadoras de los cromosomas artificiales que llevan grandes fragmentos de DNA genómico de Drosophila correspondiente a la sección 8 dcl cromosoma X. La figura 2A muestra una electroforesis de campo pulsado realizada en un gel de agarosa al 1.3 $\%$ en tampón TBE 0,5X. Este gel fue sometido a electroforcsis durante 35 horas con pulsos de 70 seg por 24 horas y $120 \mathrm{seg}$ por 11 horas a $165 \mathrm{~V}$. Esta condición permite la visualización de los cuatro cromosomas más pequeños de $\boldsymbol{S}$. cerevisiae.

En la figura $2 \mathrm{~A}$ se indica, con una cabeza de flecha, la posición aproximada de las bandas correspondientes a cada cromosoma artificial, según su migración electroforética.

La figura 2B, muestra los resultados obtenidos en un experimento de hibridación, cuando se usa $50 \mathrm{ng}$ de DNA del plásmido pBR322, utilizado como sonda radiactiva para la identificación por homología con la 
Tabla 1: Características relevantes de los clones YAC, que contienen DNA genómico de la sección 8 del cromosoma X de D. melanogaster.

\begin{tabular}{|c|c|c|c|c|c|}
\hline \multirow[b]{2}{*}{$\begin{array}{l}\text { Nombre del } \\
\text { Clon }\end{array}$} & \multirow[b]{2}{*}{$\begin{array}{c}\text { Tamaño } \\
(\mathrm{kb})\end{array}$} & \multirow[b]{2}{*}{$\begin{array}{l}\text { Ubicación } \\
\text { Citológica }\end{array}$} & \multirow[b]{2}{*}{$\begin{array}{l}\text { Vector } \\
\text { de } \\
\text { clonado }\end{array}$} & \multicolumn{2}{|c|}{$\begin{array}{c}\text { Tipo de Libreria } \\
\text { DNA genómico de }\end{array}$} \\
\hline & & & & $\begin{array}{c}\text { embrión } \\
\text { digerido con } \\
\text { NotU. }\end{array}$ & $\begin{array}{c}\text { moscas adultas } \\
\text { digerido con } \\
\text { EcoRI. }\end{array}$ \\
\hline YAC I, DYN(04-21 & 370 & $8 \mathrm{~B} 3 ; \mathrm{Cl}$ & pYAC5 & + & -- \\
\hline YAC II, DYE01-42 & 325 & $8 \mathrm{C} 13-14 ; \mathrm{D} 10-11$ & pYAC4 & -- & + \\
\hline YAC III, DYR07-36 & 350 & $8 \mathrm{Al} ; \mathrm{C} 2-3$ & pYCA4 & -- & + \\
\hline YAC IV, DYN28-60 & 260 & 8D9-11; E3-4 & pYCA5 & + & -- \\
\hline YAC V, DYR16-01 & 210 & 8D10-11; E6-9 & pYAC4 & -- & + \\
\hline YAC VI, DYR19-61 & 230 & $8 \mathrm{E} 1-2 \backslash \mathrm{F} 1-2$ & pYAC4 & -- & + \\
\hline YAC VII, DYN17-61 & 180 & $8 \mathrm{E} 3-4 ; \mathrm{F} 9-10$ & pYAC5 & + & -- \\
\hline
\end{tabular}

Tabla 2. Hibridación del fragmento PCR de 0.67 kb con los cromosomas artificiales.

\begin{tabular}{|lcc|}
\hline Nombre del clon & $\begin{array}{c}\text { Hibridación con sonda radioactiva } \\
\text { fragmento de } 0.67 \mathrm{~kb}\end{array}$ \\
\hline AB1380 (control) & -- & -- \\
YAC I, DYN04-21 & -- & -- \\
YAC II, DYE01-42 & +++ & + \\
YAC III, DYR07-36 & ++ & -- \\
YAC IV, DYN28-60 & +++ & -- \\
YAC V, DYR16-01 & +++ & - \\
YAC VI, DYR19-61 & +++ & -- \\
YAC VII, DYN17-61 & +++ & \\
\hline
\end{tabular}

+ : señal de hibridación positiva. -- : señal de hibridación negativa.

parte plasmidial de cada YAC. Esto permite la ubicación precisa de los clones YAC en el cariotipo electroforćtico de la levadura. En la membrana mostrada en la figura $2 \mathrm{~B}$ se aprecian las señales de hibridación detectadas por pBR322, correspondientes a los clones DYN(4-21 de 370 $\mathrm{kb}$ (canal 2), DYE01-42 de $325 \mathrm{~kb}$ (canal 3), DYR07-36 de $350 \mathrm{~kb}$ (canal 4), DYN28-60 de $260 \mathrm{~kb}$ (canal 5), DYR16-01 de $210 \mathrm{~kb}$ (canal 6), DYR19-61 de $230 \mathrm{~kb}$ (canal 7) y DYN17-61 de $180 \mathrm{~kb}$ (canal 8). En tanto que, no se observa señal de hibridación con DNA genómico de levadura (cepa $\mathrm{AB} 1380$ ) usado como estándar de tamaño molecular (canal 1).

Análisis de hibridación de los cromosomas artificiales de levadura con un fragmento de $0,67 \mathrm{~kb}$ de $D$. melanogaster.

Con el fragmento de $0,67 \mathrm{~kb}$ de D. melanogaster, amplificado mediante PCR, utilizando como partidores dos oligonucleótidos correspondientes a una región conservada del gen de hexoquinasa A de rata, se realizó un 
Figura 1. Ubicación de los YACs en la sección 8 del cromosoma I (X) de Drosophila melanogaster.

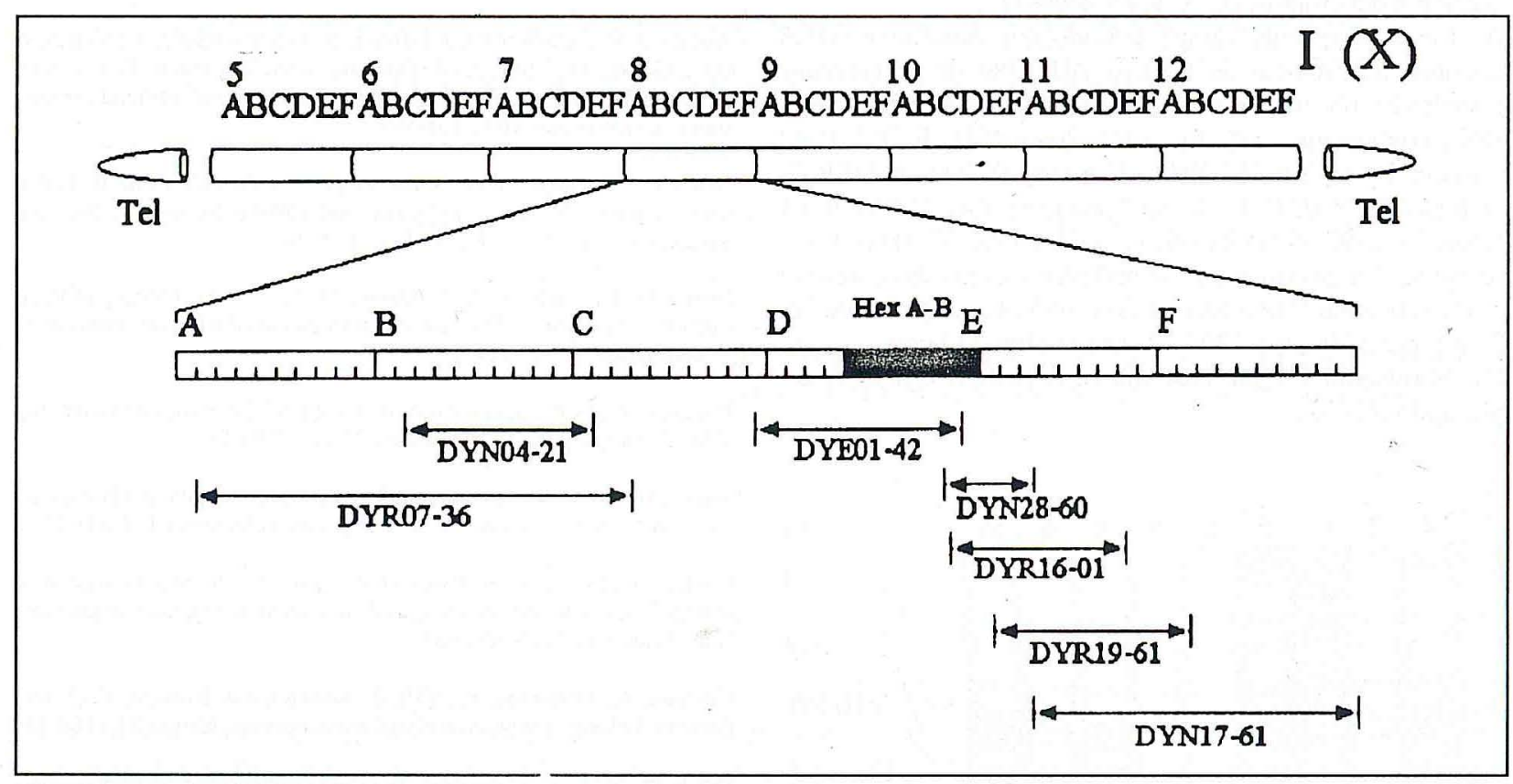

análisis de la sección 8 del cromosoma X que debicra contener el locus Hex A-B. Para cllo. los siete clones que contienen cromosomas artificiales de levadura fucron resucltos mediante clectroforesis de cainpo pulsado. en condiciones que permiten una mejor resolución de los cuatro cromosomas más pequeños de levadura y con cllo de los cromosomas artificiales que tienen tamaños moleculares comprendidos entre 180 y $37($ ) $\mathrm{kb}$ (ver tabla 1).

La tabla 2 mucsi ra los resul tados de una hibridación de los cromosomas de levadura con el fragmento de (0.67 $\mathrm{kb}$ marcado con ${ }^{32} \mathrm{P}$-dCTP. La sonda detecta dos débiles señales de hibridación. Un análisis de superposición de las autoradiografías. reicla que dichas señalcs corresponden al cromosoma artificial Y AC II de Icradura (clon DYE() I42), el cual se ubica en la región citológica 8C13-14: D1011 (tabla 1). Además. no se detcctan bandas de hibridación con la cepa $\mathrm{AB} 1380$, usada como cstándar de tamaño molecular y como control negativo del cxperimento. Estos resultados indican que la secuencia de $0,67 \mathrm{~kb}$ de Drosophila, que ticne similitud con hexoquinasa A de rata (demostrada por hibridación con cDNA de hexoquinasa $\mathrm{A}$ de rata), se ubica en alguna zona de estas $325 \mathrm{~kb}$ y la localización cxacla en esta amplia región no puede ser determinada por este método. Sin embargo, cabe destacar que la ubicación citológica del clon Y AC II coincide con la ubicación del locus Hex A-B detcrminada por métodos citogenćticos.

El análisis de los clones YAC usando como sonda el fragmento PCR de $0.67 \mathrm{~kb}$ de Drosophila mostró que la sonda detecta una débil scñal de hibridación con el clon YAC II (DYE()1-42 de $325 \mathrm{~kb}$ ). lo cual coincide con la ubicación citológica dada previamente para los genes Hex A-B. La señal de hibridación obtcnida es específica ya que sólo aparece en los cánales. y en la banda correspondiente, que conticnen DNA de csic YAC (ver tabla 2) y no en todas las muestras y en bandas que pudicran indicar hibridación cruzada con los genes de levadura. La sonda no detecta scĩal de hibridación en los clones YAC I, YAC III, YAC IV, YAC V, YAC VI y YAC VII. Sin embargo, seg.n la ubicación citológica de cada YAC (tabla l y figura 2), dos clones, YAC IV y V, prescntan una pequeña región de sobrclapamiento con cl clon YAC II en la región D)-11. En conjunto estos datos permilen acotar la ubicación de los genes Hex A-B a las bandas C13-14;D8 cn la sección 8 del cromosoma X de Drosophila (ver figura 1). Por otra partc. la débil scĩal de hibridación detectada por la sonda en el clon II podría deberse a que sólo una pequeña zona de las $325 \mathrm{~kb}$ abarcada por cstc YAC prescntan identidad con el fragmento PCR de $0.67 \mathrm{~kb}$. Para definir la región de hibridación con exactitud y precisión a nircl molecular cs neccsario realizar un análisis de restricción que corte el inserto de dicho clon en varios fragmentos y subclonar el fragmento positivo en un vector adccuado.

El uso de los cromosomas artificiales de levadura y la tćcnica de separación de DNA cromosómico intacto mediante clectroforesis de campo pulsado, entrega elementos esenciales para el estudio de la organización de los genomas complejos en una amplia gama de aspectos. La ubicación de un segmento de DNA de Drosophila, en una 
Figura 2. Análisis de hibridación de DNA genómico de la sección 8 del cromosoma X de Drosophila.

A) Electroforesis de campo pulsado que muestra el DNA cromosómico intacto de la cepa $\mathrm{AB} 1380$ de $\boldsymbol{S}$. cervisiae (canales 2 y 10), usado como estándar de tamaño molecular, y el DNA cromosómico intacto d elos clones YAC II DYE01-42 (canales 1 y 4), YAC I DYN04-21 (canal 3), YAC III DYR0736 (canal 5), YAC IV DYN28-60 (canal 6), YAC V DYR16-01 (canal 7), YAC VI DYR19-61 (canal 8), YAC VII DYN 17-61 (canal 9). La electroforesis se realizó en un gel de agarosa al 1,3\% en tampón TBE $0,5 X$ corrido a 165 Volts con pulsos de 7070 seg por 24 horas y $120-120 \mathrm{seg}$ por otras 11 horas.

B) Hibridación del gel mostrado en la parte A con DNA del plásmido $\mathrm{pBR} 322$.
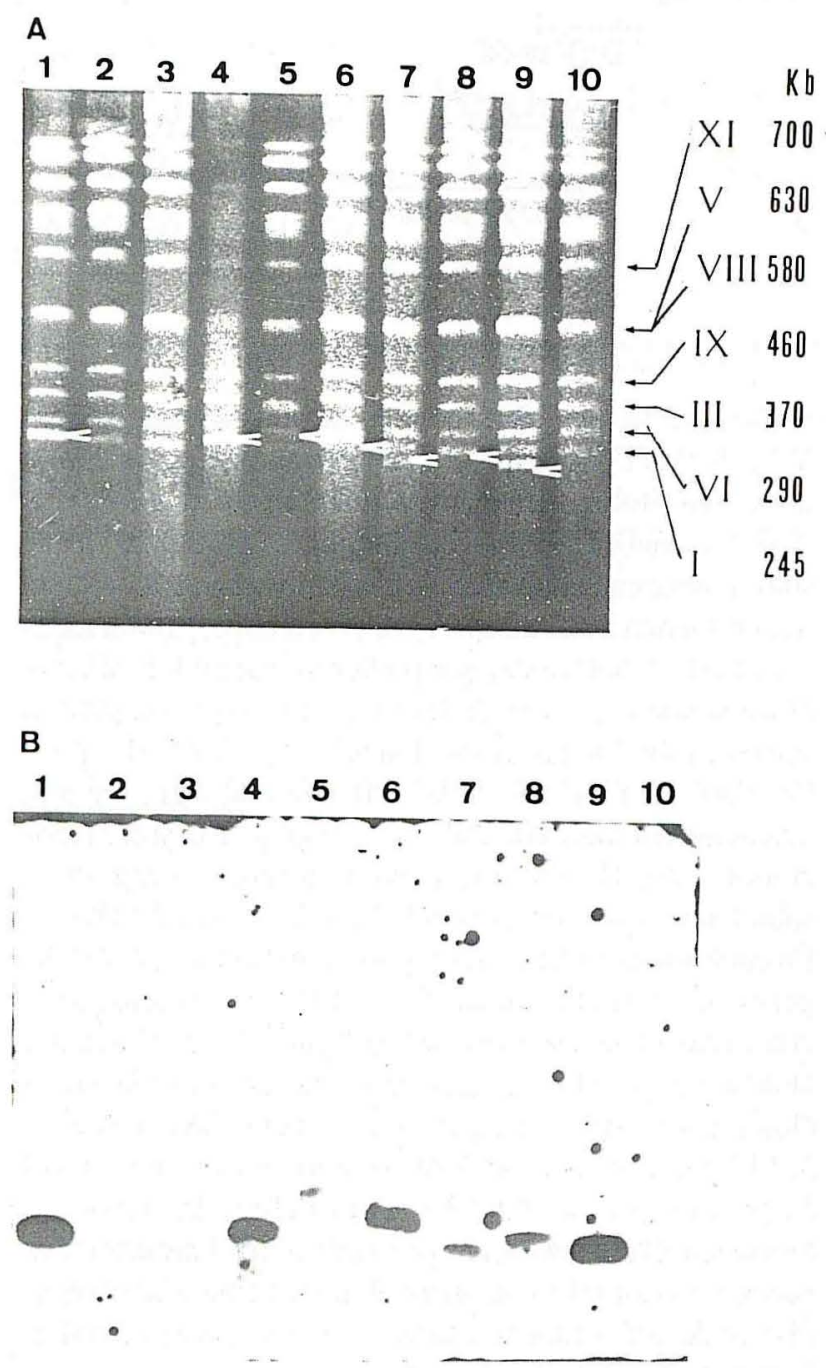

región cromosómica definida es una de sus aplicaciones dentro de una gran número de ellas.

\section{REFERENCIAS}

Ajioka, J. W.; Smoller, D. A.; Jones, R. W.; Carulli, J. P.; Vellek, A. E.C., Garza, D.; Link, A. J.;Duncan, I. W. Y. ; Hartl, D. L. (1991) Drosophila genome project: One-hit coverage in yeast artificial chromosomes. Chromosoma $100: 495-509$

Broach, J.; Pringle, J. \& Jones, E. (1991). Part C. Table II: List of mapped genes. In: The molecular and cellular biology of the yeast Saccharomyces. Vol 1. Eds C. S. H. L. Press.

Burke D. T.; Carle, G. F. \& Olson, M. V. (1987). Cloning of large segments of exogenous DNA into yeast by means of artificial chromosome vectors. Science 236:806-812

Burke, D.T. (1990). Special section: Yeast artificial chromosome cloning. YAC cloning: Options and problems. GATA 7:94-99

Burke, D. T. \& Olson, M. V. (1991). Preparation of clone libraries in yeast artificial chromosome vectors. Methods in Enzymol.194:251-270

Carle, G.F.; Frank, M. \& Olson, M.V. (1986). Electrophoretic separation of large DNA molecules by orthogonal-field-alternation gel electrophoresis. Nuc. Acids. Res. 12:5647-5664

Coulson, A.; Waterson, R.; Kiff, J.; Sulston, J.\& Kohara, Y. (1988). Genome linking with yeast artificial chromosomes. Nature 335:184-186

Feinberg, A. P. \& Vogelstein, B. (1983) A technique for radiolabeling DNA restriction endonuclease fragments to high specific activity. Anal. Biochem. 132:6-13

Fothergill-Gilmore, L. A. \& Michels, P. A. M. (1993). Evolution of glycolysis. Prog. Biophys. Molec. Biol. 59: 105- 235

Garza, D.; Ajioka, J.W.; Burke, D.T.\& Hartl, D.L. (1988). Mapping the Drosophila genome with yeast artificial chromosomes. Science 246: 641646

Haini, C.; Kiefel, P.; Yee, J. \& Duncan, I. (1994). A yeast artificial chromosome clone map of the Drosophila genome. Genetics 136:13851399

Hartl, D. L.; Ajioka, J. W.; Cai, H.; Lohe, A. R.; Lozovskaya, E. R.; Smoller, D. A. \& Dumcan I. W. (1992). Towards a Drosophila genome map. TIG $8: 70-75$

Murray, A. W.\& Szostak, J. W. (1983). Construction of artificial chromosomes in yeast. Nature 305:189-193

Sambrook, J.; Fritsch, E. \& Maniatis, T. (1989). Molecular cloning: A laboratory manual. Second edition. Cold Spring Harbor Laboratory.

Schwab, D. A. \& Wilson, J. E. (1989). Complete amino acid sequence of ratbrain hexokinase, deduced from the cloned cDNA, and proposed structure of a mammalian hexokinase. Proc. Natl. Acad. Sci. USA. 86: 2563-2567

Schwartz, D. C.\& Cantor, C. R. (1984). Separation of yeast chromosomesized DNAs by pulsed field gradient gel electrophoresis. Cell 37:67-75

Southern, E. (1975)Detection of specific sequences among DNA fragments separated by gel electrophoresis. J. Mol. Biol. 98:503-517

Voelker, R. A.; Langley, C. H.; Leigh-Brown, A. J. \& Ohnishi, S. (1978). New data on allozyme loci in D. melanogaster. DIS 53:200 